\title{
Encouraging older people to engage in resistance training: a multi-stakeholder perspective
}

\author{
SIMONE PETTIGREW*, ELISSA BURTON $\dagger$, KAELA FARRIER $\dagger$, \\ ANNE-MARIE HILL $\dagger$, LIZ BAINBRIDGE $\dagger$, PHIL AIREY $\ddagger$, \\ GILL LEWINৎ and KEITH D. HILL†
}

\begin{abstract}
Resistance training is an important aspect of healthy ageing, yet participation rates are especially low among older people. Strategies are needed to ensure resistance training programmes are attractive to and appropriate for this target group. To inform the development of such strategies, individual interviews $(\mathrm{N}=42)$ and focus groups (four groups, $\mathrm{N}=37$ ) were conducted with 79 Western Australians representing four stakeholder groups: instructors who deliver resistance training programmes to older people, health practitioners, policy makers and seniors. Results indicate that the need for personalised attention in the establishment and maintenance phases of a resistance training programme can constitute both a positive and negative aspect of older people's experiences. The negative aspects were identified as a series of tensions between the need for personalised attention and (a) the desire to participate in physical activity within social groups, (b) a preference for activity variation, (c) a dislike for large centres where personalised guidance is often available yet the surroundings can be considered unappealing, (d) cost issues and (e) the need for flexibility in attendance. Recommended strategies for overcoming these tensions include disseminating information about the benefits of resistance training in later life to increase motivation to participate, identifying additional methods of integrating resistance training into group exercise formats, making gyms more attractive to older people and providing non-gym alternatives for resistance training.
\end{abstract}

KEY WORDS - resistance training, barriers, gyms, retention strategies.

* School of Psychology, Curtin University, Perth, Australia.

$\uparrow$ School of Physiotherapy and Exercise Science, Curtin University, Perth, Australia.

$\$$ Council on the Ageing (WA), Perth, Australia.

$\S$ School of Nursing, Midwifery and Paramedicine, Curtin University, Perth, Australia. 


\section{Introduction}

Despite the well-known benefits of resistance training (also known as strength training) for physical and mental health in general, and functional capacity in particular, participation rates among the general population are low (Humphries, Duncan and Mummery 2010; Mayer et al. 2011; Merom et al. 2012). Rates are especially low among older people (Bennie et al. 2016), which is of concern given the tendency towards sarcopenia in later life and the ability of resistance training to address this condition (Landi et al. 2014). In Australia, the context of the present study, current national guidelines recommend that those aged $6_{5}$ years and older 'should accumulate at least $3^{0}$ minutes of moderate intensity physical activity on most, preferably all, days' and 'be active every day in as many ways as possible, doing a range of physical activities that incorporate fitness, strength, balance, and flexibility' (Commonwealth of Australia 2014). However, it is estimated that only around 8 per cent of older Australians engage in the minimum of two sessions of resistance training per week recommended by the World Health Organization (Bennie et al. 2016; World Health Organization 2011).

Some work has examined the main factors influencing older people's decisions to participate in resistance training (Burton et al. 2016a, 2016b; Dean et al. 2007; Henwood et al. 2011; Viljoen and Christie 2015; Yardley et al. 2007). This research has demonstrated that numerous physical, psychological, social and environmental factors influence older people's decisions to engage in (or avoid) resistance training. In the Australian context, a general desire to be fit and healthy, referrals from medical/health practitioners, and the management of health conditions were found to be the dominant motivators, with falls prevention and weight management also rated as important (Burton et al. 2016a). The most frequently nominated barriers included pain, injury and feeling too old. These findings are generally consistent with those of studies conducted in other countries (Dean et al. 2007; Pedersen et al. 2017; Viljoen and Christie 2015; Yardley et al. 2007).

The development of strategies to increase participation in resistance training among older people requires a detailed understanding of the factors influencing if and how resistance training opportunities are made available and promoted to this population. To some extent this has been addressed in research examining the experiences of older people participating in group exercise programmes such as the Living Longer Living Stronger programme in Australia (Vrantsidis et al. 2014) and the EnhancesFitness programme in the United States of America (PetrescuPrahova et al. 2017). However, evidence from the perspective of service 
providers responsible for facilitating older people's engagement in resistance training is lacking (Hawley-Hague et al. 2016). Understanding the views and experiences of these stakeholders is critical to optimise the provision of age-appropriate resistance training opportunities.

To address the current deficit in knowledge relating to service providers' views and experiences, and provide deeper insight into potential strategies to increase participation, the present study aimed to investigate various stakeholders' perceptions of how older people can be encouraged to commence and continue resistance training. These stakeholders included exercise practitioners who deliver resistance training services, general health practitioners, and those involved in policy development and implementation. In addition, older people were included in the study to access their views on the issues raised by the other stakeholders.

\section{Method}

An exploratory approach to data collection was adopted in recognition of the paucity of evidence relating to practitioners' and policy makers' views of the role of resistance training in later life and how older people can be encouraged to incorporate recommended levels of resistance training into their lifestyles. A combination of interviews and focus groups was used to allow extensive discussions of relevant topics and the probing of new issues as they arose. Including a diverse range of stakeholders provided triangulation to increase the trustworthiness of the findings (Lincoln and Guba 1985; Mays and Pope 2000). Table 1 summarises the sample profile. Ethics approval for the study was granted by the Curtin University Human Research Ethics Committee and informed written consent was obtained from all participants.

\section{Phase I}

Initially, individual interviews were conducted with resistance training instructors and managers of centres that offer resistance training programmes for older people. Due to the operational commitments of these individuals and the large geographical coverage of metropolitan and regional Western Australia, individual interviews were deemed the most feasible data collection approach. In addition, this method permitted detailed accounts to be provided by those who regularly interact with seniors during resistance training sessions.

Invitation emails were distributed to Western Australian fitness centres with resistance training programmes designed for and targeted at older 
T A B LE 1. Sample profile

\begin{tabular}{lrc}
\hline Participant type & N & Female (\%) \\
\hline RT instructor & 18 & 67 \\
Centre manager & 24 & 63 \\
Other RT practitioner & 8 & 75 \\
Policy representative & 5 & 80 \\
Senior & 24 & 79 \\
Total & 79 & 71 \\
\hline
\end{tabular}

Note: RT: resistance training.

people. Those centres with staff replying to express interest in participating in the study were then contacted by telephone to schedule an interview. The interviews with those based in the metropolitan area were conducted faceto-face on centre premises, and those with staff based at regional centres were conducted by telephone (four instructors and five centre managers). In total, 18 instructors and 24 centre mangers were interviewed, two-thirds of whom were female. This gender distribution reflects the higher proportion of females working in this industry in Australia (Australian Bureau of Statistics 2012 ). The average interview duration was 20 minutes for instructors and 27 minutes for centre managers.

The interview guides for instructors and centre managers comprised a series of topics raised with interviewees during the discussions. A funnel approach was used to allow relevant issues to emerge spontaneously wherever possible (Gorden 1969). This involved initially asking broad, openended questions relating to the current services offered to older people in their centres and the way in which these services are delivered and promoted. This typically resulted in wide-ranging discussions about the needs and preferences of older clients and how the centre attempted to overcome any barriers and capitalise on opportunities to service this population segment better. Specific topics listed in the interview guide that were used as prompts if the issue was not spontaneously raised included interviewees' perceptions of the effectiveness of their current efforts to cater to older people, suggestions for possible improvements and potential methods of encouraging seniors in general to participate in resistance training.

\section{Phase 2}

To provide additional context to the issues discussed by the instructors and centre managers, a second data collection phase was undertaken that involved four focus groups with other relevant stakeholders. Two groups were conducted with those working in related fields: one with health practitioners (e.g. physiotherapists and home care eligibility assessors; $\mathrm{N}=8$ ) and 
the other with individuals involved in the development and implementation of policies relating to physical activity in Western Australia $(\mathrm{N}=5)$. As was the case for the centre staff, potential interviewees were contacted by email to invite them to participate in the study.

The other two groups were conducted with older people (group size: $\mathrm{N}=$ 13, $\mathrm{N}=11$; gender split: $\mathrm{N}=19$ females, $\mathrm{N}=5$ males). Recruitment efforts included advertisements disseminated via community radio, newsletters and large retirement villages. Despite these broad-ranging approaches, most of those electing to participate were female. This gender skew is consistent with previous research in this field (Burton et al. 2016b), and is likely to reflect a combination of women being more prevalent in the older population due to greater longevity (World Health Organization 2014) and being more willing research participants in general (Galea and Tracy 2007).

Consistent with the approach used for the individual interviews, the interview guides for the focus groups adopted a funnel approach to encourage participants to raise issues they felt were most relevant to the subject under discussion. For the practitioner/policy groups, initial questions were posed relating to the participants' prior experiences with facilitating physical activity among older people and their knowledge and beliefs relating to the benefits of physical activity for seniors. When participants made references to resistance training, this topic was then discussed in greater detail to investigate the extent to which this form of physical activity is accepted and endorsed among these stakeholder groups. For the seniors' groups, the interview guide contained general questions about changes experienced by people in their later years, followed by questions about their engagement in and attitudes to physical activity. Specific questions were then posed about beliefs and behaviours relating to resistance training and the implications for future strategies to promote higher levels of participation. The average duration of the practitioner/policy makers' groups was 71 minutes and the average duration of the seniors' groups was 77 minutes.

\section{Analysis}

The interviews and focus groups were audio-recorded and the recordings were subsequently transcribed verbatim and imported into NVivo 11 (qualitative data analysis software for coding and analysis: QSR International). Consistent with the exploratory nature of the study, an inductive approach to coding was used to allow meaning to be derived from the data rather than commencing with a pre-conceived theoretical framework (Glaser and Strauss 1967; Huberman and Miles 1994). This approach involved the initial development of a coding hierarchy that was informed by issues identified in the extant literature, with additional codes introduced progressively to reflect the topics 
discussed in the interviews and focus groups. Given the need for emergent coding, a single coder (the first author) performed the coding task.

During analysis, all transcripts were read in their entirety and individual nodes (the location at which text is assigned to particular codes within NVivo) were interrogated to provide deeper insights into the issues discussed. In addition, NVivo's text and matrix search functions were used to explore themes that arose during analysis. Consistent with recommendations (Mays and Pope 2000; Pope, Ziebland and Mays 2000), a reflexive approach to data analysis was adopted that involved considering numerous alternative themes to make sense of the data and discussing these with other members of the research team. Through this process, various tensions were identified that encompassed the difficulties associated with aligning older people's priorities and concerns with the requirements of current physical activity recommendations and the logistics of service delivery. Potential solutions to these tensions were identified and are outlined below.

\section{Results}

Across all stakeholder groups there was a general understanding that while some seniors actively engage in resistance training and understand the benefits that can accrue from this form of exercise, most do not. This situation was attributed to a lack of understanding among older people of the numerous health benefits associated with resistance training, a lack of prior experience with this form of exercise and a fear of being injured.

I'd never heard of resistance training. (Female, Seniors focus group (FG))

We do have a lot of the older generation who are still stubborn and don't believe in coming to the gym. We also get a diversity of people; some will say, 'I'm too old for that, I've gone past my use-by-date'. (Female, Instructor, Regional area)

If they have hurt themselves in some way, maybe tried something a little too heavy and hurt themselves, then they get scared of doing that again ... That is quite a big fear when it comes to weights. (Female, Instructor, Metropolitan area)

Low awareness of the benefits of resistance training was noted to be often accompanied by a preference for other forms of exercising that are considered at least equally beneficial but more convenient and enjoyable. Walking was the most frequently mentioned 'competitor activity', with some also mentioning swimming, dancing and cycling.

Male 1: Walking is pretty easy to do, isn't it? You don't have to turn yourself inside out. 
Male 2: You don't need any equipment.

Female: You can do it when you've got your own time.

Male 2: Yes, that's true. (Seniors FG)

I think yeah walking is often done because that is something they can easily do from the home, they've always been doing it. Whereas they might be given a resistance training programme but just aren't familiar with it, so then they don't do it. (Female, Policy FG)

In addition, resistance training was often discussed as being perceived as primarily meant for other population segments. In particular, it was described as being associated with body building rather than achieving and maintaining functionality in older age:

The older generation - you talk strength training, the first image that comes into their mind is a body builder alright, or an Olympic lifter or whatever. And they don't want to be like that. No, strength is about being able to get in and out of the car easily. Strength is about being able to get up the stairs, being able to get in and out of your chair. (Female, Centre Manager, Metropolitan area)

I'm always saying the importance of keeping your bones strong. Some of them come in here [saying] 'I don't want to do weights, I don't want to get big and bulky, I just want to do cardio'. And that's when I have to explain [about] keeping your bones strong. (Female, Fitness Centre Manager, Metropolitan area)

\section{Tensions}

Numerous other limiting factors were also identified that, in combination with a lack of awareness of the benefits of resistance training for older people, are likely to discourage both the commencement and continuation of resistance training among this group. These factors may be best described as tensions that are difficult for seniors to resolve because they involve the incompatibility of resistance training with personal preferences and lifestyle habits. These tensions constitute challenges for service providers tasked with overcoming these barriers to encourage more seniors to commence resistance training and to minimise attrition among those who choose to participate. The identified tensions are depicted in Figure 1 and outlined below.

The one aspect of resistance training that was relevant to all the identified tensions was a need for some degree of individualised attention, at least in the early stages of commencement. This was seen as both a facilitating and limiting factor affecting seniors' participation in resistance training activities. Especially for the many older people who have not had previous experience with resistance training, the process of commencing participation should ideally involve receiving information and guidance tailored to their health history, exercise experience and current health status 


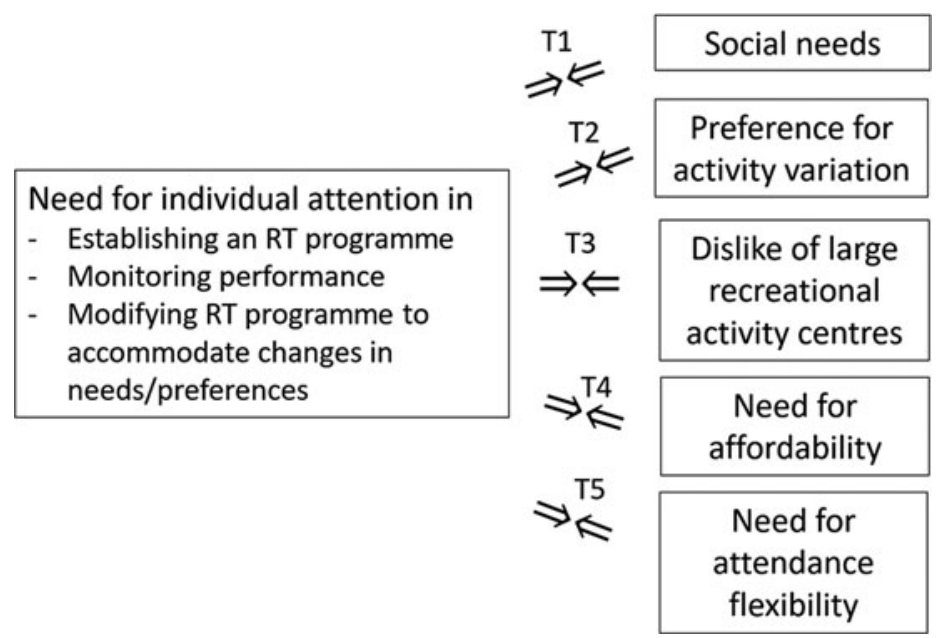

Figure 1. Tensions discouraging seniors' participation in resistance training Notes: RT: resistance training. T: tension.

(Signorile 2011). Similarly, continuation ideally involves monitoring to assess compliance, ensure correct technique and provide modified instructions as progress is made or set-backs occur. The need for these tailored inputs was recognised by both those providing resistance training services and those receiving them, although there were varying accounts of the extent to which individual attention is provided.

I cap my programme to 12 people per session so they manage the people and go around and make sure everyone's doing things correctly and they're comfortable and corrected and progressed accordingly. (Male, Centre Manager, Metropolitan area)

When you start, you go through all this rigmarole to find out what you need. Like balance and on one leg and closed eyes, and all that. Then there's no comeback. Six months later you're still doing the same thing. They still haven't rechecked you. (Female, Seniors FG)

Tension I: The need for individual attention versus a desire for social interaction. The first tension related to the potentially conflicting goals of personalised attention and the substantial social benefits of group exercise. All the stakeholders involved in the study spontaneously mentioned the importance of social interaction for seniors' involvement in physical activity programmes.

It seems to me, social is the biggest attraction. Whatever programme you want to introduce, social is the biggest attraction. (Female, Seniors FG) 


\section{Simone Pettigrew et al.}

So there's still the social aspect of it as well, because that, apart from the benefits of the actual exercise, that's probably the biggest benefit for a lot of them. They actually meet people and then they go off and have coffees and things like that together. (Male, Centre Manager, Metropolitan area)

Although resistance training can be and often is delivered in group contexts that provide social interaction, this format makes individual attention more difficult to achieve and can result in sub-standard experiences for participants. Examples were provided of various scenarios in which individuals were not able to receive the guidance they needed because of the difficulties associated with supervising multiple participants simultaneously. This reflects the tendency for group resistance training contexts to come to resemble other group physical activity classes where technique instructions are more limited and generally not customised to the needs of individual participants:

We have had several [dementia sufferers] in the past ... I'd love to see [them] succeed, but it's very demanding for the trainers who often feel that they're ignoring the rest of the group at the expense of explaining things repetitively. (Female, Fitness Centre Manager, Metropolitan area)

This current group where I'm going, I'm appalled there's no conversation around using your core muscles, there's no conversation around your stance when you're doing free weights. I know enough from other places and gleaning and reading and telly and what have you that they should be doing that every time. (Female, Seniors FG)

Tension 2: The need for individual attention versus a desire for variation. Another aspect of an individualised resistance training programme is the often more limited exercise repertoire relative to other forms of physical activity. Boredom and a desire for activity variation were commonly nominated as factors that adversely impact on seniors' willingness to commence or continue with resistance training.

Female 1: Exercise is boring. Gym's no good for us...

Female 2: Exercise that's incorporated in dancing is really good fun, but exercise for the sake of exercise is boring. (Seniors FG)

They get bored easily. (Female, Fitness Centre Manager, Regional area)

Instead, activities that can be varied by day, week and season, and that can be done with different companions (e.g. partners, friends and dogs), can be more attractive. Walking was often seen to fulfil this need for variation because of the ability to vary the route taken and the changing landscape over time. By comparison, the need for ongoing supervision of a resistance training programme and the need to perform repeatedly specific resistance 
exercises to realise the potential physiological benefits can limit the amount of variation that can be experienced.

Tension 3: The need for individual attention versus a dislike of large centres. Large centres have the potential to schedule staff members to be on hand to provide individual-level supervision and guidance. Compared to attempting to undertake a resistance programme at home, this can assist in ensuring that training programmes remain relevant to individuals' needs over time and that appropriate feedback on technique is provided.

We reassess every couple of months as well, [and] also when we're out on the floor as well talking - how are you coming along with your programme? Are you finding it too easy? Have you progressed further than you thought? So we'll give you a couple more exercises or give you a whole new programme or alter this, alter that. (Male, Fitness Centre Manager, Metropolitan area)

However, as indicated earlier, this potential for personalised attention does not necessarily translate to the level of service that is needed and/or expected by older people, who can have complex health issues and may need to have information provided regularly. In addition, centres may be primarily staffed by younger instructors who can appear to be on 'automatic pilot' and lack empathy for the needs of older clients:

Female 1: In most cases in the gym you're being trained by your jolly grandson. Female 2: It's just like they press a button and a spiel comes out.

Female 3: They're only babies. (Seniors FG)

Overall, large centres were perceived as being unattractive to seniors who can be alienated by other patrons and find the noise levels uncomfortable. Alternative physical activity options, especially those involving exercising outdoors, can be much more appealing to members of this generation.

We've got a lot of young lads dropping their weights and growling and stuff. So the ones [seniors] that are not so adaptable would move on from that. The seniors that are a little bit temperamental as well - I've seen some of them have a bit of sense of entitlement. Somebody's using this machine and they need it. They will be like, 'How long do you have left?', and they'll stand there 'til they're finished. But it's not really that good gym etiquette. And they might get grumpy if the music's too loud, so things like that will put them off. (Male, Instructor, Metropolitan area)

[I like] getting outside in the fresh air and the wind and the sun and the green and the birds. (Female, Seniors FG)

Tension 4: The need for individual attention versus a need for affordability. It was generally recognised that the cost of exercise programmes is a major issue for older people and, as a result, resistance training services need to 


\section{Simone Pettigrew et al.}

be priced at a level that is considered acceptable to those living on constrained budgets.

It's all a cost thing for those oldies - whether they can afford the six months [fee], for example. (Female, Fitness Centre Manager, Metropolitan area)

Female 1: If it's in a gym, sometimes cost can be a factor.

Female 2: Oh yeah.

Female 3: Oh yes. (Seniors FG)

Some seniors prefer the one-on-one services of exercise specialists (such as physiotherapists or exercise physiologists) to develop and monitor their resistance training programmes:

I go to a physio and he gives me exercises that I do every morning ... I go once a month because of maintenance. (Female, Seniors FG)

However, this option is not financially viable for many and is not viewed as a financial priority for others. Other alternatives include the often lessqualified and over-subscribed instructors available at local gyms and fitness centres, self-administering a programme or avoiding resistance training altogether.

If you don't have access to expensive things like physio and OTs [occupational therapists] to give you a really tight exercise prescription, you're going to either do nothing or guess and potentially hurt yourself. (Female, Policy FG)

Tension 5: The need for individual attention versus a need for attendance flexibility. The time constraints experienced by many older people were acknowledged by each of the stakeholder groups. In particular, child-care responsibilities, volunteer work and extended travel were described as often preventing seniors from commencing or adhering to resistance training programmes.

You would think that old people would have all the time in the world, but they are actually quite busy, so I know that is one element ... They are quite busy with looking after their grandchildren. (Female, Instructor, Metropolitan area)

In addition, chronic and acute health problems among members of this age group can result in a need to suspend attendance while recuperating. Reflecting these issues, preference was expressed by the seniors for programmes that allow them to opt-in and opt-out whenever they choose.

They should cut out the membership for a year, and you just pay when you go. (Female, Seniors FG) 
However, this operational model is not well-suited to the economic realities of both smaller service providers and larger exercise centres that need to ensure revenues cover the costs associated with scheduling enough staff to provide the levels of service required by patrons. Designing programmes that allow personalised attention inevitably involves limiting the number of attendees, which is problematic when individuals do not attend despite registering for sessions.

We had one the other day, I think three didn't show up and there's three places that someone else could have had. That's always a constant issue that we've tried to tackle. (Male, Physiotherapy Centre Manager, Metropolitan area)

\section{Proposed solutions}

The study participants' suggestions for overcoming these tensions to increase resistance training among older people can be categorised as macro- and micro-level strategies. The macro-level strategies relate to longer-term approaches to modifying the broader socio-cultural and physical environments to be more conducive to resistance training in later life. The micro-level strategies involve specific actions that can be taken to improve outcomes for individuals in the shorter term.

Macro-level strategies. The most fundamental requirement identified by the study participants was for large-scale education campaigns to increase community awareness of the benefits of resistance training in general and in older age in particular. Such campaigns were proposed to be needed to modify cultural norms such that resistance training is universally recognised as a vital component of a healthy lifestyle for all adults. It was recognised that campaigns would need to be delivered via media that are effective in reaching this demographic segment.

What we're actually talking about is societal norms, changes in culture, changes in expectations of people. (Male, Policy FG)

It has to be education and it can only be education through, I think, the television media because that's what's watched most. Pensioners watch TV. (Male, Centre Manager, Metropolitan area)

I would say advertising in the right media for them - the seniors' magazines or seniors' newspapers. (Female, Instructor, Regional area)

It was noted by the study participants that education campaigns directed at seniors should also target others in their lives to ensure older people are receiving appropriate advice about incorporating resistance training into their lifestyles. Nominated important others included family members and health professionals, which are groups that have been identified in 


\section{Simone Pettigrew et al.}

previous research as being important in supporting the resistance training decisions of older people (Yardley et al. 2007). In terms of the latter category, references were made in the present study to doctors and pharmacists who come into regular contact with older people but may prioritise the prescription of medication over more preventive approaches that include resistance training.

I think it's the environmental factors, so whether or not the family is supportive of that or not. So some families are like, 'Mum, Dad, you're actually at the stage where you shouldn't be doing those exercises because you're going to be at the risk of hurting yourself or having further falls or something like that'. I think it's those environmental factors which also contribute to why they don't engage in those type of exercises. (Female, Practitioner FG)

This is a generation that believes anything their doctor tells them as well, so if we can get the GPs [general practitioners] on board it would be fantastic. (Female, Practitioner FG)

Due to current negative views about resistance training among many older people, the suggestion was made by various study participants that education campaigns should be developed very carefully to avoid using alienating terminology. The words 'weights' and 'weights training' were considered to be intimidating, resulting in a need to reframe resistance training as a process of achieving functional fitness.

You've got to be very careful when you say strength training. As soon as you say to an old person we're going to go there and we're going to do weights - uh-uh, no you don't. You bring them in and it can be very scary for someone to come in and think oh my goodness we're going to be picking up a dumbbell or a bar. So you have to be careful how you word things and how you get people in because you can't scare them off. (Female, Fitness Centre Manager, Metropolitan area)

People just don't realise that they can still get stronger, that they can still improve on what they're doing now and then they can still kind of have their independence and then increase their mobility and function. So yeah, just making people aware that that's actually still a possibility is probably a big one. (Male, Centre Manager, Metropolitan area)

After public education campaigns, the second major macro-level strategy suggested by the study participants was further progress towards the reconceptualisation of exercise programmes to include greater variation and the incorporation of strength components into everyday activities and other activities enjoyed by seniors. This involves reduced focus on formal resistance training sessions and greater integration of different types of activity.

Female: The Prime Movers [seniors' physical activity programme] is a good example because all their instructors are seniors. 
Female: Lovely social atmosphere, a lot of laughs, different changes of activity, good music.

Facilitator: So when you say changes of activity, so variation?

Female: Yeah. So we'd do some bending and skipping and walking and stretching and a bit of weights.

Facilitator: So is the trick to making resistance training more senior friendly to embed it in other kinds of activity as well, rather than just making it all about the weights?

Female: $\quad$ Yeah, probably.

Male: $\quad$ Yeah. (Seniors FG)

The recent trend of resistance equipment being installed in outdoor walking areas was raised as a model for achieving both the integration of resistance training with other enjoyed activities (in this case walking) and taking the gym to the people. Promoting the use of resistance bands was also nominated by numerous study participants as an under-appreciated means of encouraging people to engage in resistance training in their homes and in a variety of ways to alleviate boredom. Finally, the increasing availability of exercise DVDs suited to different kinds of health conditions was mentioned as being conducive to people being able to undertake appropriate resistance training exercises in their own homes, especially for those without ready access to facilities.

It's not a gym or nothing, there's a lot of things that you could do. Even carrying a weight when you're walking for your hip health or doing some [can of beans] or go and buy some elastics and attach them to your stairwell. (Female, Policy FG)

I once had a phone call from a lady who was living in the country. She had osteoporosis and had seen a specialist and was told to be doing some activity for strength and balance and we were trying to work over long distance. We ended up getting her an osteoporosis DVD which had falls and balance exercises and some strength exercises. So the DVDs are relevant for a variety of conditions. (Male, Practitioner FG)

Micro-level strategies. Other suggested approaches to increasing participation in resistance training related to specific strategies for delivering services in ways that are attractive to seniors and encourage continuation. Of primary importance, and as alluded to earlier, was the embedding of opportunities for social interaction throughout and between resistance training sessions. Such opportunities can include the provision of tea and coffee at the end of sessions and regular outings or seminars.

We try to organise a few social outings, occasions and fun exercise days where they get to run around and be idiots instead of just doing the structured exercise, showing them that there's different ways that you can actually do your exercise. (Female, Practitioners FG) 


\section{Simone Pettigrew et al.}

I can set up a seminar here in this room, we can fit 20 people in here and put a PowerPoint and show and put on a free coffee and a bickie [biscuit/cookie] type of thing. (Male, Physiotherapy Centre Manager, Metropolitan area)

Other nominated strategies involved identifying opinion leaders or champions within the client group to promote the sessions to outsiders and assist others within the group as needed. This was reported to build commitment and loyalty among these clients by giving them an additional role that adds purpose to their attendance, while also encouraging them to bring along others who become new members.

What we used to do, because we were trying to create self-management as well, was in the groups, at different stages we'd say, 'Alright, come along next week and we want you to be able to tell the group what to do while we're on holidays so we know you can do it yourselves'. And we'd get the group owning, delivering or telling an exercise to the other people. (Female, Practitioner FG)

Get them to bring a friend along, because it's their friend. If it is a true friend they'll follow their friend because they trust that friend and then you've just got to work through those barriers once they're in your clinic. (Female, Practitioner FG)

The final micro-level strategy recommended by the study participants was the provision of summaries or checklists that outline useful methods of integrating resistance training into everyday activities. Examples suggested included doing sit-to-stand exercises at the conclusion of every book chapter and standing on one leg while the kettle boils to improve balance.

\section{Discussion}

Low levels of participation in resistance training among older people necessitate intensive efforts to encourage the commencement and continuation of this form of activity to achieve the associated health and functional benefits. Most previous research has accessed older people's views of the various barriers that reduce their willingness and/or ability to engage in resistance training (Burton et al. 2016a, 2016b; Dean et al. 2007; Henwood et al. 2011 ; Viljoen and Christie 2015). The present study supplements this work by including the perspectives of a range of stakeholders involved in the provision of resistance training services to older people. Five primary tensions were identified, represented in Figure 1, that are likely to (a) provide additional insights into current low levels of participation and (b) suggest potential means of overcoming existing obstacles to greater participation. The various macro- and micro-level strategies suggested by the study participants constitute a range of options that may be used to address the identified tensions. 
Reflecting the findings of other recent research (Bampton, Johnson and Vallance 2016), the study participants recognised the importance of providing personalised assistance for older people engaging in resistance training to ensure they have access to safe and effective programmes. This need for individual attention was at the core of the five identified tensions that were found to act as barriers to engagement. A major challenge is to provide personalised service within the budgetary constraints of the senior segment of the population. The 'train the trainer' approach suggested by some of the study participants could assist in this regard by skilling some clients to assist others to reduce delivery costs (Buman et al. 2011).

The public education campaigns strongly recommended by the study participants would also be important in ensuring the economic viability of such programmes. Greater public awareness of the benefits of resistance training for healthy ageing may soften the ground for future policy changes relating to subsidising these services and the availability of rebates by health and life insurance agencies. In addition, appreciating the importance of resistance training to their health is likely to be a key determinant of seniors' willingness to bear the inconvenience and costs associated with this form of physical activity. Such campaigns would ideally emphasise the benefits of resistance training over and above the outcomes that can be achieved with other forms of exercise. This approach would be consistent with current guidelines recommending being active in a variety of ways, including resistance training (Commonwealth of Australia 2014; World Health Organization 2011). Of importance will be the way information is imparted to ensure non-intimidating and acceptable terms are used in communications (Hawley-Hague et al. 2016). For example, although the sector has gravitated towards the use of the term 'resistance training', this may not be meaningful to older people and other language may need to be used to convey the nature of the activity and its associated benefits. Formative research will be important in identifying appropriate ways of communicating effectively with older people about resistance training in a manner that is both informative and motivating.

The modification of gyms to accommodate the needs of the older client better would appear to be a further priority, especially in terms of the processes used to provide personalised information and guidance at key stages of an individual's resistance training journey (Lübcke, Martin and Hellström 2012). Ensuring access to knowledgeable, mature instructors who can empathise with the needs and preferences of older clients is likely to be a welcome approach (Hawley-Hague et al. 2014; Tulle and Dorrer 2012). The findings suggest that a complementary strategy would be to increase the non-gym alternatives available to older people. Such alternatives would ideally include those that facilitate the inclusion of resistance 


\section{Simone Pettigrew et al.}

training into other activities (e.g. the location of resistance training equipment alongside walking paths or outdoor parks specifically designed for older people; Sales et al. 2017) and create the opportunity for variation over time to prevent boredom (e.g. DVDs and brochures that provide information about the diverse activities that can be performed in the home). The need for flexibility in attendance could also be better accommodated by the availability of these forms of non-gym alternatives. Once again, investment in large-scale education campaigns that communicate the multiple and substantial health benefits of resistance training would assist in encouraging older people to take advantage of these alternative forms of resistance training.

A final consideration is the provision of resistance training opportunities for those experiencing cognitive decline. A growing evidence base demonstrates the benefits of resistance training for both preventing and slowing cognitive impairment (Gallaway et al. 2017; Smolarek et al. 2016). For example, dementia sufferers can achieve significant improvements in their performance of activities of daily living through participation in resistance training (Garuffi et al. 2013). This highlights the importance of ensuring older people, their health-care providers and their families are aware of these benefits to increase participation rates. However, the results of the present study indicate that it may be necessary to schedule dedicated classes for those experiencing cognitive impairment to ensure all clients receive the levels of individualised attention they require to optimise the benefits of resistance training.

\section{Limitations and future research directions}

The main limitations of this study relate to the qualitative approach and the involvement of only Western Australian stakeholders. Both these characteristics limit the generalisability of the findings to the broader populations of older people and resistance training service providers. The large sample size for a qualitative study provides some assurance that the findings may be useful to those attempting to increase seniors' resistance training participation in similar cultural contexts, however additional research in other locations would be beneficial to assess the extent to which the identified strategies may be effective elsewhere. A further limitation is the gender skew resulting in a primarily female sample. Future research could focus more specifically on the needs and experiences of male seniors and service providers to provide a more comprehensive picture of relevant issues.

In conclusion, proactive strategies are required to address low rates of resistance training participation among older people. The results of the 
present study indicate that developing strategies that overcome the logistical limitations associated with the delivery of personalised assistance for programme development and refinement should be an important component of future efforts. These strategies are likely to include disseminating information about the importance of resistance training in later life to increase motivation, identifying methods of satisfactorily combining tailored information with group exercise formats, making gym environments more attractive to older people, and providing acceptable and effective nongym alternatives.

\section{Acknowledgements}

The authors thank the fitness centre managers and staff, practitioners, policy employees and older people who participated in the interviews and focus groups. Thanks are also extended to Bob and Shirley who were the consumer representatives on the research group overseeing the research project. The work was supported by the Western Australia Health Promotion Foundation (Healthway Research Project Grant Number 24208). The funder had no role in the study design, data collection, analysis and interpretation of the data, writing the report, or the decision to submit the article for publication. The authors report no conflicts of interest in this work.

\section{References}

Australian Bureau of Statistics 2012. Employment in Sport and Recreation, Australia, August 20I I. Catalog No. 4148.o, ABS, Canberra.

Bampton, E. A., Johnson, S. T. and Vallance, J. K. 2016. Correlates and preferences of resistance training among older adults in Alberta, Canada. Canadian Journal of Public Health, 107, 3, e272-7.

Bennie, J. A., Pedisic, Z., van Uffelen, J. G., Charity, M. J., Harvey, J. T., Banting, L. K., Verger, I., Biddle, S. J. H. and Eime, R. M. 2016. Pumping iron in Australia: prevalence, trends and sociodemographic correlates of muscle strengthening activity participation from a national sample of 195,926 adults. PLOS ONE, 11, 4, eo153225.

Buman, M. P., Giacobbi, P. R., Jr, Dzierzewski, J. M., Aiken Morgan, A., McCrae, C. S., Roberts, B. L. and Marsiske, M. 2011 . Peer volunteers improve long-term maintenance of physical activity with older adults: a randomized controlled trial. Journal of Physical Activity and Health, 8, supplement 2, S257-66.

Burton, E., Farrier, K., Lewin, G., Pettigrew, S., Hill, A.-M., Airey, P., Bainbridge, L. and Hill, K. D. 2016a. Motivators and barriers for older people participating in resistance training: a systematic review. Journal of Aging and Physical Activity, 25, 2, $311-24$.

Burton, E., Lewin, G., Pettigrew, S., Hill, A.-M., Bainbridge, L., Farrier, K., Langdon, T., Airey, P. and Hill, K. D. 2016b. Identifying motivators and barriers to older community-dwelling people participating in resistance training: a crosssectional study. Journal of Sports Sciences, 35, $15,1523^{-32 .}$ 


\section{Simone Pettigrew et al.}

Commonwealth of Australia 2014. Physical Activity Recommendations for Older Australians (65 Years and Older). Available online at http://www.health.gov.au/ internet/main/publishing.nsf/content/health-pubhlth-strateg-phys-act-guidelines \#chba [Accessed 12 February 2017].

Dean, R. N., Farrell, J. M., Kelley, M. L., Taylor, M. J. and Rhodes, R. E. 2007. Testing the efficacy of the theory of planned behavior to explain strength training in older adults. Journal of Aging and Physical Activity, 15, 1, 1-12.

Galea, S. and Tracy, M. 2007. Participation rates in epidemiologic studies. Annals of Epidemiology, 17, 9, 643-53.

Gallaway, P.J., Miyake, H., Buchowski, M. S., Shimada, M., Yoshitake, Y., Kim, A. S. and Hongu, N. 2017. Physical activity: a viable way to reduce the risks of mild cognitive impairment, Alzheimer's disease, and vascular dementia in older adults. Brain Sciences, 7, 2, 22.

Garuffi, M., Costa, J. L. R., Hernández, S. S. S., Vital, T. M., Stein, A. M., Santos, J. G. D. and Stella, F. 2013. Effects of resistance training on the performance of activities of daily living in patients with Alzheimer's disease. Geriatrics $\mathcal{E}^{\circ}$ Gerontology International, 13, 2, 322-8.

Glaser, B. and Strauss, A. 1967. The Discovery of Grounded Theory. Aldine Publishing Company, Chicago.

Gorden, R. L. 1969. Interviewing: Strategy, Techniques, and Tactics. Dorsey Press, Illinois.

Hawley-Hague, H., Horne, M., Campbell, M., Demack, S., Skelton, D. A. and Todd, C. 2014. Multiple levels of influence on older adults' attendance and adherence to community exercise classes. The Gerontologist, 54, 4, 599-610.

Hawley-Hague, H., Horne, M., Skelton, D. A. and Todd, C. 2016. Older adults' uptake and adherence to exercise classes: instructors' perspectives. Journal of Aging and Physical Activity, 24, 1, 119-28.

Henwood, T. I. M., Tuckett, A., Edelstein, O. and Bartlett, H. 2011 . Exercise in later life: the older adults' perspective about resistance training. Ageing $\mathcal{E}$ Society, $\mathbf{3} 1,8$, 1330-49.

Huberman, A. and Miles, M. 1994. Data management and analysis methods. In Denzin, N. and Lincoln, Y. (eds), Handbook of Qualitative Research. Sage, Thousand Oaks, California, 428-44.

Humphries, B., Duncan, M. J. and Mummery, W. K. 2010. Prevalence and correlates of resistance training in a regional Australian population. British Journal of Sports Medicine, 44, 9, 653-6.

Landi, F., Marzetti, E., Martone, A. M., Bernabei, R. and Onder, G. 2014 . Exercise as a remedy for sarcopenia. Current Opinion in Clinical Nutrition $\mathcal{E}^{\circ}$ Metabolic Care, 17 , $1,25^{-31 .}$

Lincoln, Y.S. and Guba, E. G. 1985. Naturalistic Inquiry. Sage, Beverly Hills, California.

Lübcke, A., Martin, C. and Hellström, K. 2012 2. Older adults' perceptions of exercising in a senior gym. Activities, Adaptation $\mathcal{E}$ Aging, 36, 2, 131-46.

Mayer, F., Scharhag-Rosenberger, F., Carlsohn, A., Cassel, M., Müller, S. and Scharhag, J. 2011. The intensity and effects of strength training in the elderly. Deutsches Arzteblatt International, 108, 21 , 359-64.

Mays, N. and Pope, C. 200o. Assessing quality in qualitative research. British Medical Journal, 320, 7226, 50-2.

Merom, D., Pye, V., Macniven, R., van der Ploeg, H., Milat, A., Sherrington, C., Lord, S. and Bauman, A. 2012. Prevalence and correlates of participation in fall prevention exercise/physical activity by older adults. Preventive Medicine, 55, 6, $613-7$. 
Pedersen, M. T., Vorup, J., Nistrup, A., Wikman, J. M., Alstrom, J. M., Melcher, P. S., Pfister, G. U. and Bangsbo, J. 2017 . Effect of team sports and resistance training on physical function, quality of life, and motivation in older adults. Scandinavian Journal of Medicine Eं Science in Sports, 27, 8, 852-64.

Petrescu-Prahova, M. G., Eagen, T.J., Fishleder, S. L. and Belza, B. 2017 . Enhance ${ }^{\circledR}$ Fitness dissemination and implementation: 2010-2015: a scoping review. American Journal of Preventive Medicine, 52, 3, S295-9.

Pope, C., Ziebland, S. and Mays, N. 2000. Analysing qualitative data. British Medical Journal, 32o, 7227, $114^{-6 .}$.

Sales, M., Polman, R., Hill, K. D. and Levinger, P. 201 7. A novel exercise initiative for seniors to improve balance and physical function. Journal of Aging and Health, 29, 8, $1424-43$.

Signorile, J. F. 2011 . Bending the Aging Curve: The Complete Exercise Guide for Older Adults. Human Kinetics, Champaign, Illinois.

Smolarek, A., Ferreira, L. H. B., Mascarenhas, L. P. G., McAnulty, S. R., Varela, K. D., Dangui, M. C., de Barros, M. P., Utter, A. C. and Souza-Junior, T. P. 2016. The effects of strength training on cognitive performance in elderly women. Clinical Interventions in Aging, $11,749-54$.

Tulle, E. and Dorrer, N. 2012. Back from the brink: ageing, exercise and health in a small gym. Ageing EO Society, 32, 7, $1106-27$.

Viljoen, J. E. and Christie, C. J. 2015 . The change in motivating factors influencing commencement, adherence and retention to a supervised resistance training programme in previously sedentary post-menopausal women: a prospective cohort study. BMC Public Health, 15, 236.

Vrantsidis, F., Hill, K., Haralambous, B., Renehan, E., Ledgerwood, K., Pinikahana, J., Harper, S. and Penberthy, M. 2014 . Living Longer Living Stronger ${ }^{\mathrm{TM}}$ : a communitydelivered strength training program improving function and quality of life. Australasian Journal on Ageing, 33, 1, 22-5.

World Health Organization 2011. Global Recommendations on Physical Activity for Health: 65 Years and Above. Available online at http://www.who.int/dietphysical activity/publications/recommendations65yearsold/en [Accessed 12 February $2017]$.

World Health Organization 2014. World Health Statistics 2014. Available online at http://apps.who.int/iris/bitstream/10665/11 2738/1/9789240692671_eng.pdf [Accessed 27 December 2016].

Yardley, L., Donovan-Hall, M., Francis, K. and Todd, C. 2007. Attitudes and beliefs that predict older people's intention to undertake strength and balance training. Journals of Gerontology: Psychological Sciences and Social Sciences, 62B, 2, P1 19-25.

\section{Accepted 27 February 20I8; first published online Io April 2018}

Address for correspondence:

Simone Pettigrew,

School of Psychology,

Curtin University, Kent St, Bentley, 6102,

Perth, Western Australia, Australia

E-mail: Simone.pettigrew@curtin.edu.au 